\title{
HIV INFECTION OF HUMAN CARTILAGE
}

\author{
D. G. CAMPBELL， P. LI， R. D. OAKESHOTT \\ From the Royal Adelaide Hospital, the Institute of Medical and Veterinary Science and \\ the Queen Elizabeth Hospital, Adelaide, Australia
}

$I^{\mathrm{n}}$ nfection of human cartilage with HIV in vivo has not previously been reported. Specimens of articular cartilage taken at postmortem from ten patients who were HIV-positive were examined. Two had AIDS and eight were believed to have stage- 2 disease.

The standard polymerase chain reaction (PCR) protocol was modified to allow semiquantitative analysis of the samples. Oligonucleotide primers labelled with ${ }^{32} \mathrm{P}$ gamma-ATP were used to detect a segment of HIV DNA and a control DNA gene segment (HLA genome) to estimate the ratio of infected cells. The ${ }^{32} \mathrm{P}$-labelled PCR products were separated on acrylamide gels and visualised directly by autoradiography and computer densitometry.

Infection of human cartilage in vivo was demonstrated in nine of the ten samples in which the PCR analysis was positive. The other did not react sufficiently to produce detectable radiolabelled PCR product despite repeated DNA digestion and extraction. Cartilage infected with HIV could be a potential source of HIV when used in operations.

J Bone Joint Surg [Br] 1996;78-B:22-5.

Received 12 May 1995; Accepted 15 June 1995
Cartilage allografts are an important source of tissue for reconstructive surgery of the head and neck and have been used successfully in osteochondral allografts. Cartilage is also an important contaminant of many bone allografts. It is avascular and the mucopolysaccharide matrix forms a barrier to blood and immune cells. The success of cartilage allografts may therefore be due to the relative isolation of the chondrocyte in this matrix (McGlynn and Sharpe 1981). Viable cartilage allograft has been identified after seven years (Kandel et al 1985) and biopsies of osteochondral allografts have shown live chondrocytes six years after transplantation (Czitrom, Keating and Gross 1990).

Human chondrocytes lack a CD4 receptor and therefore are not considered to be susceptible to HIV infection through a CD4-dependent mechanism (Bujia et al 1993b). Other mechanisms leading to possible HIV infection of chondrocytes have been examined. Cell-free HIV infection of chondrocytes has been investigated by two research centres with differing results (Ikeuchi et al 1990; Bujia et al 1993a) and the susceptibility of chondrocytes to HIV infection in vitro is uncertain.

Infection of human cartilage with HIV in vivo has not been described. Our aim was to examine cartilage from patients infected with HIV for evidence of infection with this virus.

\section{MATERIALS AND METHODS}

Specimens were received from ten postmortems. All the patients were HIV-antibody-positive; two had AIDS and eight were believed to have stage- 2 disease. One patella was obtained from each patient. Donor blood was washed from the sample during collection. The articular cartilage of all specimens was macroscopically normal.

The standard polymerase chain reaction (PCR) protocol was modified to allow semiquantitative analysis of samples. Simultaneous amplification and detection of a single-copy human gene and an HIV sequence have been developed to allow a semiquantitative assay of HIV infection when the cell number or DNA input is unknown (Lee et al 1991). This method uses an internal control to validate the efficiency of the PCR reaction and to determine the HIV copy number relative to that of the DNA of the input cell.

A further modification of the PCR uses ${ }^{32} \mathrm{P} 5^{\prime}$ endlabelled synthetic oligonucleotide primers so that the transfer and hybridisation steps used in other methods are 
omitted and the number of PCR cycles is therefore decreased. This is then followed by direct autoradiography of gel-resolved products (Arrigo et al 1989).

Details of methods. One gram of articular cartilage was crushed with a mortar and pestle and incubated for 72 to 78 hours at $37^{\circ} \mathrm{C}$ in a lysis solution consisting of $100 \mathrm{mM}$ $\mathrm{NaCl}, 10 \mathrm{mM}$ TRIS.Cl (pH 8), 25 mM EDTA (pH 8), 0.5\% sodium dodecylsulphate (SDS) and $0.1 \mathrm{mg} / \mathrm{ml}$ proteinase$\mathrm{K}$. The solution was extracted three times with phenylchloroform-isoamylalcohol (25:24:1) and the DNA was precipitated by ethanol sodium acetate. The pellet was rinsed with $70 \%$ ethanol, dried and resuspended in $50 \mu \mathrm{l}$ TE (10 mM Tris pH 7 and $1 \mathrm{mM}$ EDTA). The DNA content was measured spectrophotometrically.

A control curve for the quantitative PCR method was constructed using dilutions of HIV from infected human lymphocytes. The chronically HIV-infected cell line H3B (Li and Burrell 1992) was spiked with non-infected HUT78 cells (NIH AIDS Research and Reference Reagent Programme, ERC Bioservices Corp, Rockville, Maryland). Chromosomal DNA extracted from mixed HUT-78 and H3B cells, with tenfold dilutions of $10^{-2}$ to $10^{-5} \mathrm{H} 3 \mathrm{~B}$ cells, was analysed in duplicate with each PCR analysis of clinical samples, which were assessed in triplicate. A fresh PCR reaction master mix and control cell DNA were used for each repeat analysis. A new control curve was constructed for each new reaction mixture or radiolabelled probe pair. A negative control derived from HUT-78 cell chromosomal DNA was included in each PCR reaction.

Oligonucleotide probes GH26 (Saiki et al 1985) and SK38 (Kellogg and Kwok 1990) were independently endlabelled on the $5^{\prime}$ terminus with ${ }^{32} \mathrm{P}$ gamma-ATP ( 1 to $\left.5 \times 10^{6} \mathrm{cpm}\right)$. Labelled nucleotides were used immediately or stored overnight at $-20^{\circ} \mathrm{C}$ in lead pigs.

The PCR reaction mixture of $100 \mu$ l contained $5 \mu \mathrm{l}$ $10 \times$ Thermus Aquaticus (Taq) buffer (Bresatec, Adelaide, South Australia), $2.25 \mathrm{mmol} \mathrm{MgCl}_{2}, 1 \mathrm{mmol}$ of each of the four deoxynucleoside triphosphates (Perkin Elmer Cetus, Roche Molecular Systems, New Jersey), 0.04 units of Taq polymerase (Bresatec), and $5 \mu \mathrm{l}$ of each primer dilution. The hot-start technique was used with the reaction mixture with less enzyme and DNA, overlaid with ampliwax PCR gem 100's (Perkin Elmer) and heated to $60^{\circ} \mathrm{C}$ for 5 to 10 minutes. The reaction tubes were cooled to room temperature and then an upper reaction mixture consisting of $0.4 \mu \mathrm{l}$ Taq polymerase (5.5 units/ $\mu \mathrm{l}$; Bresatec), water and $5 \mu \mathrm{g}$ DNA was added using a positive displacement pipette (Bresatec) to aliquot the DNA.

Each amplification cycle consisted of 1.5 minutes at $95^{\circ} \mathrm{C}$, one minute at $56^{\circ} \mathrm{C}$ and two minutes at $72^{\circ} \mathrm{C}$ followed by ten minutes at $72^{\circ} \mathrm{C}$. Twenty-five cycles were used in all experiments.

Ten microlitres of each sample and a ${ }^{32} \mathrm{P}$ gamma-ATP radiolabelled molecular weight marker (pUC 19 DNA restricted with Hpa II: Bresatec) were added to $2 \mu$ l of loading buffer. The samples and marker were subjected to $8 \%$ polyacrylamide gel electrophoresis at $100 \mathrm{~V}$ for 60 to 120 minutes. After running, the gel was dried at $80^{\circ} \mathrm{C}$ under vacuum for one hour and exposed to autoradiographic film (XAR-5, Kodak, Rochester, New York) without enhancing screen for 90 to 180 minutes at room temperature.

A clean phosphor screen (Molecular Dynamics, Sunnyvale, California) was exposed to the radiolabelled gels for 18 hours at room temperature. The phosphor screen was scanned with a PhosphorImager (ImageQuant, model 400B; Molecular Dynamics) using Molecular Dynamics ImageQuant version 3.0 software. Net optical densities for the specific HIV and HLA bands were determined by volume integration with manual background subtraction for each sample. The results of HIV and HLA band intensities (in $\mathrm{OD} / \mathrm{mm}^{2}$ ) for each sample were analysed.

HIV and HLA band intensities for the control cell dilutions were plotted for each H3B/HUT-78 cell dilution. CAcricket graph computer software (1990 Computer Associates International Inc, San Diego, California) was used to construct a simple regression curve which determined the ratio of HIV-infected cells from the radiolabelled PCR product of clinical samples.

\section{RESULTS}

Autoradiography showed delineation of the 115 base pair HIV-1-gag region and 242 base pair segment of the HLADQ- $\alpha$ genome with no interfering bands (Fig. 1). HUT-78 cell DNA included as a negative control was amplified in all experiments and the 115 base pair HIV-1-gag region

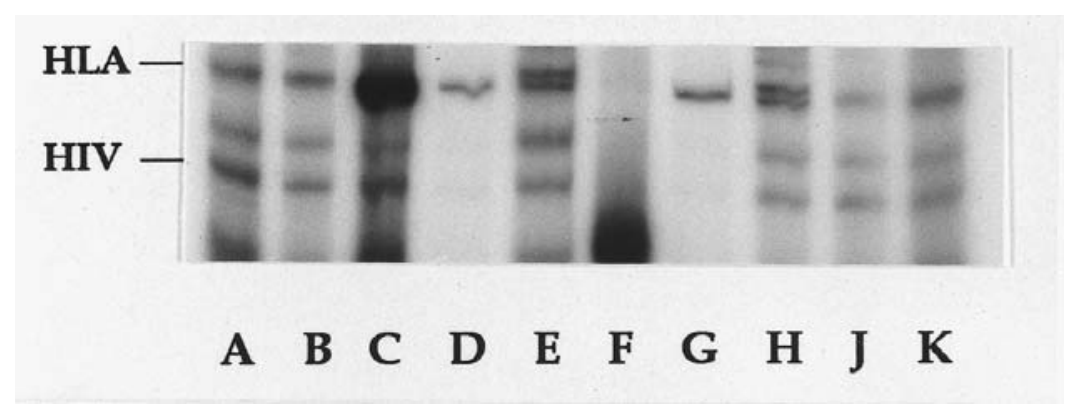

Fig. 1

PCR coamplification of cartilage from ten HIV infected patients. Detection of the 115 base pair HIV segment indicates HIV infection with incorporation of HIV into the chromosomal DNA of the host cells. A 242 base pair segment of the HLADQ- $\alpha$ genome is included as an internal control of PCR efficiency and to determine the HIV copy number relative to cell copy number. 
was not detected.

The two primer pairs detected from cartilage specimens and H3B cell dilutions had HIV and HLA specific bands that were successfully amplified. Detection of the HIV1-gag region from nine samples indicates in vivo infection of human cartilage with HIV.

The PCR product was not detected from case 6 after three PCRs and repeated DNA digestion and extraction. Samples were examined in triplicate but the PCR product was obtained from cases 1, 2 and 4 in only one experiment after repeated DNA extraction.

\begin{tabular}{|c|c|}
\hline Case & $\begin{array}{l}\text { HIV infected } \\
\text { cells } \log _{10}\end{array}$ \\
\hline 1 & -2 \\
\hline 2 & -2 \\
\hline 3 & -3 \\
\hline 4 & $<-5$ \\
\hline 5 & -3 \\
\hline 6 & - \\
\hline 7 & -5 \\
\hline 8 & -5 \\
\hline 9 & -2 \\
\hline 10 & -2 \\
\hline
\end{tabular}

The results of semiquantitative PCR analysis are summarised in Table I. The calculated ratio of infected cells to uninfected cells was $10^{-2}$ to $<10^{-5}$.

\section{DISCUSSION}

In this study HIV was detected in all samples of human cartilage in which PCR analysis was achieved. One of the ten samples did not react sufficiently to produce a detectable radiolabelled PCR product despite repeated DNA digestion and extraction. This may have been related to the quality of the extracted DNA or to the presence of inhibitors.

Human cartilage is avascular and the specimens examined were intact and macroscopically normal. They were thoroughly washed and were not contaminated with blood or other body fluids. It is therefore assumed that the HIV DNA detected was present in infected chondrocytes. In nine of the ten samples in which the PCR product was obtained HIV infection was identified in $1.0 \%$ to $0.001 \%$ of cells. In our study a finding of up to $1 \%$ HIV infection of chondrocytes in vivo is consistent with in vitro findings of HIV infection in cells of mesenchymal origin (Ikeuchi et al 1990; Mellert et al 1990).

The mechanism of HIV infection of chondrocytes in vivo remains unknown. The mean 'pore' size of human cartilage is approximately the size of the serum albumin molecule (Maroudas 1979). Thus, cell-to-cell HIV transmission is prevented but cell-free infection is possible. HIV infection independent of the CD4 receptor by phagocytosis and endocytosis has been reported (Clapham et al 1989; Harouse et al 1989; Tateno, Gonzalez-Scarano and Levy 1989) and it may be that this mechanism is effective in vivo in human cartilage. The differing results of investigation of in vitro infection of human chondrocytes (Ikeuchi et al 1990; Bujia et al 1993a) are not explained by our study which suggests that chondrocytes can be infected under appropriate conditions.

Our results are consistent with the finding of the presence of HIV in synovial fluid in patients infected with this virus (Withrington et al 1987). HIV arthropathy has been described (Forster et al 1988) and chondrocyte infection may be related to this. We did not study the function and microscopic appearance of the chondrocytes and therefore the clinical role of chondrocytes infected with HIV remains unknown. Cartilage may be a potential site of systemic HIV infection. Although HIV infection from cartilage allografts has not been reported, we do not agree with Bujia et al (1993a) who suggest that they may be less likely to transmit HIV than other allografts. Cartilage allografts from donors of unknown status should be vigilantly screened for the possible presence of HIV.

We acknowledge the financial support of the Royal Australasian College of Surgeons and the Australasian Department of Employment Education and Training. We wish to thank Associate Professor J. M. Hilton, Director of the New South Wales Institute of Forensic Medicine for the supply of clinical samples from HIV-infected postmortems and Professor D. W.

Howie for his helpful comments.

No benefits in any form have been received or will be received from a commercial party related directly or indirectly to the subject of this article.

\section{REFERENCES}

Arrigo SJ, Weitsman S, Rosenblatt JD, Chen IS. Analysis of rev gene function on human immunodeficiency virus type 1 replication in lymphoid cells by using a quantitative polymerase chain reaction method. J Virol 1989;63:4875-81.

Bujia J, Meyer H, Hammer C, Wilmes E, Gurtler L. Human immunodeficiency virus cannot productively infect freshly cultured human cartilage cells. ORL J Otorhinolaryngol Relat Spec 1993a;55:222-5.

Bujia J, Pitzke P, Wilmes E, Hammer C, Gurtler L. A critical analysis of human immunodeficiency virus transmission using human cartilage allografts. Eur Arch Otorhinolaryngol 1993b;250:55-8.

Clapham PR, Weber JN, Whitby D, et al. Soluble CD4 blocks the infectivity of diverse strains of HIV and SIV for T cells and monocytes but not for brain and muscle cells. Nature 1989;337:368-70.

Czitrom AA, Keating S, Gross AE. The viability of articular cartilage in fresh osteochondral allografts after clinical transplantation. J Bone Joint Surg [Am] 1990;72-A:574-81.

Forster SM, Seifert MH, Keat AC, et al. Inflammatory joint disease and human immunodeficiency virus infection. $\mathrm{Br}$ Med J Clin Res Ed 1988;296:1625-7.

Harouse JM, Kunsch C, Hartle HT, et al. CD4-independent infection of human neural cells by human immunodeficiency virus type 1 . J Virol 1989;63:2527-33.

Ikeuchi K, Kim S, Byrn RA, Goldring SR, Groopman JE. Infection of nonlymphoid cells by human immunodeficiency virus type 1 or type 2 . J Virol 1990;64:4226-31.

Kandel RA, Gross AE, Ganel A, et al. Histopathology of failed osteoarticular shell allografts. Clin Orthop 1985;197:103-10. 
Kellogg DE, Kwok S. Detection of human immunodeficiency virus In: Innis MA, Gelfand DH, Snisky JJ, ed. PCR Protocols: a guide to methods and applications. New York: Academic Press, 1990:337-47.

Lee TH, Sunzeri FJ, Tobler LH, Williams BG, Busch MP. Quantitative assessment of HIV-1 DNA load by coamplification of HIV-1 gag and HLA-DQ-alpha genes. AIDS 1991;5:683-91.

Li P, Burrell CJ. Synthesis of human immunodeficiency virus DNA in a cell-to-cell transmission model. AIDS Res Hum Retroviruses 1992;8:253-9.

Maroudas A. Physicochemical properties of articular cartilage. In: Freeman MAR, ed. Adult articular cartilage. Kent: Pitman Medical, 1979:215-90.
McGlynn MJ, Sharpe DT. Cialit preserved homograft cartilage in nasal augmentation: a long term review. Br J Plast Surg 1981;34:53-7.

Mellert W, Kleinschmidt A, Schmidt J, et al. Infection of human fibroblasts and osteoblast-like cells with HIV-1. AIDS 1990;4:527-35.

Saiki RK, Scharf S, Faloona F, et al. Enzymatic amplification of Betaglobin genomic sequences and restriction site analysis for diagnosis of sickle cell anaemia. Science 1985;230:1350-4.

Tateno M, Gonzalez-Scarano F, Levy JA. Human immunodeficiency virus can infect CD4-negative fibroblastoid cells. Proc Natl Acad Sci USA 1989;86:4287-90.

Withrington RH, Cornes P, Harris JR, et al. Isolation of human immunodeficiency virus from synovial fluid of a patient with reactive arthritis. Br Med J Clin Res Ed 1987;294:484. 